This article was downloaded by: [Enrique Serra-Alegre]

On: 05 December 2011, At: 08:56

Publisher: Psychology Press

Informa Ltd Registered in England and Wales Registered Number: 1072954

Registered office: Mortimer House, 37-41 Mortimer Street, London W1T 3J H, UK

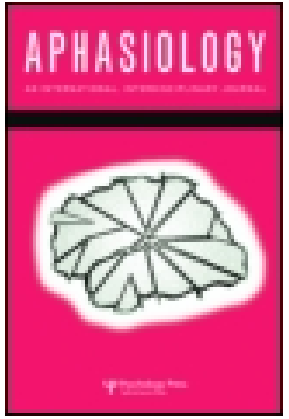

\title{
Aphasiology
}

Publication details, including instructions for authors and subscription information:

http:// www. tandfonline.com/loi/ paph20

\section{On natural metalinguistic abilities in aphasia: A preliminary study}

Carlos Hernández-Sacristán ${ }^{a}$, Vicent Rosell-Clari ${ }^{b}$, Enrique Serra-Alegre ${ }^{a} \&$ J osep Quiles-Climent ${ }^{c}$

${ }^{a}$ Department of Language and Communication, University of Valencia, Valencia, Spain

${ }^{b}$ Department of Basic Psychology, University of Valencia, Valencia, Spain

c Valencian Institute of Statistics, Valencian Autonomous Government, Valencia, Spain

Available online: 30 Nov 2011

To cite this article: Carlos Hernández-Sacristán, Vicent Rosell-Clari, Enrique Serra-Alegre \& J osep Quiles-Climent (2011): On natural metalinguistic abilities in aphasia: A preliminary study, Aphasiology, DOI:10.1080/ 02687038. 2011.630456

To link to this article: http:// dx.doi.org/ 10.1080/ 02687038.2011.630456

\section{GFirst}

\section{PLEASE SCROLL DOWN FOR ARTICLE}

Full terms and conditions of use: http://www.tandfonline.com/page/terms-andconditions

This article may be used for research, teaching, and private study purposes. Any substantial or systematic reproduction, redistribution, reselling, loan, sub-licensing, systematic supply, or distribution in any form to anyone is expressly forbidden.

The publisher does not give any warranty express or implied or make any representation that the contents will be complete or accurate or up to date. The accuracy of any instructions, formulae, and drug doses should be independently verified with primary sources. The publisher shall not be liable for any loss, actions, claims, proceedings, demand, or costs or damages whatsoever or howsoever caused 

material. 


\title{
On natural metalinguistic abilities in aphasia: A preliminary study
}

\section{Carlos Hernández-Sacristán ${ }^{1}$, Vicent Rosell-Clari², Enrique Serra-Alegre ${ }^{1}$, and Josep Quiles-Climent ${ }^{3}$}

\author{
${ }^{1}$ Department of Language and Communication, University of Valencia, \\ Valencia, Spain \\ ${ }^{2}$ Department of Basic Psychology, University of Valencia, Valencia, Spain \\ ${ }^{3}$ Valencian Institute of Statistics, Valencian Autonomous Government, \\ Valencia, Spain
}

\begin{abstract}
Background: Natural metalinguistic abilities, which are put into play without explicit instructions, constitute the cognitive basis for a "reflexive" use of language, a particular manifestation of the executive function when applied to language and verbal behaviour. This reflexive use entails a specific attentional activity by speakers and hearers with regard to linguistic outputs, and an intentional experience-based control over the language use. Putting into play natural metalinguistic abilities can be considered a significant factor for explaining different kinds of adaptive processes.

Aims: Preliminary research on natural metalinguistic abilities as manifested in people with aphasia will be described in this paper. Our research has been conceived to provide an integrated protocol exploring techniques and skills that reveal a reflexive use of language. Some of these techniques and skills have recently been studied in aphasiology using different methods and from different theoretical perspectives.

Methods \& Procedures: The natural metalinguistic abilities of 21 aphasic individuals with different aetiology and severity were examined by means of a protocol including a test and two questionnaires. Scores were statistically analysed to determine the reliability and validity of these instruments as a measure of the metalinguistic abilities available.

Outcomes \& Results: Cronbach's alpha coefficient enables us to prove the consistency of the test and questionnaires. There were high correlations between the Boston Diagnostic Aphasia Examination (BDAE) global scores and scores from the test and questionnaires. The severity of aphasia and the aphasia type (as determined through BDAE) contribute significantly to explaining differences observed in the scores from the test and questionnaires.
\end{abstract}

Conclusions: The results of this preliminary study permit us to conclude that a combined exploration of metalinguistic abilities can be justified for the assessment of aphasia. Moreover, the examination of preserved metalinguistic abilities provides an alternative way for assessing the degree of severity of impaired communicative behaviour by people

Address correspondence to: Carlos Hernández-Sacristán, Department of Language and Communication, University of Valencia, 32 Blasco Ibanez Avenue, 46010 Valencia, Spain. E-mail: carlos.hernandezsacristan@uv.es

The present study includes results from the Research Projects HUM2007-66074-C02-02, FFI200802592FILO and FFI2011-25947 financially supported by the Spanish Ministry of Science and Innovation. We would like to express special gratitude to Silvia Hille, Ray Foster, and Gary Smith for their observations and their revision of an initial version of this paper.

(C) 2011 Psychology Press, an imprint of the Taylor \& Francis Group, an Informa business http://www.psypress.com/aphasiology

http://dx.doi.org/10.1080/02687038.2011.630456 
with aphasia. Our procedure, presumably, will also be useful for suggesting new factors when designing therapeutic programmes.

Keywords: Aphasia assessment; Metalinguistic abilities; Reflexivity; Executive function; Metacognitive processing; Language impairment.

The general aim of this paper is to explore natural metalinguistic abilities as manifested in people with aphasia. Natural metalinguistic abilities have been considered to be a particular manifestation of the executive function (Barkley, 1997, 2001) when applied to language and verbal behaviour: i.e., "a special type of executive process, involved in controlling and manipulating language" (Harley, Jessiman, MacAndrew, \& Astell, 2008, p. 322). This is tantamount to viewing metalinguistic abilities as an aspect of metacognitive processing. The relationship between metalinguistic abilities and executive function or "metacognition" is basically assumed here. However, in order to define more specifically the notion of metalinguistic abilities that we are using here, let us consider the rationale sustaining our proposal by introducing some basic considerations as regards the general context within which this approach must be understood.

It is generally assumed that to explain verbal behaviour one must consider hidden or not overtly manifested dimensions underlying this behaviour. In our view one of these dimensions - and probably the most significant one - can be identified as the experiential component associated with language and verbal behaviour. Experiencing verbal behaviour means establishing a psychological "distance" or "polarisation" between "person and symbolic vehicle" (Werner \& Kaplan, 1978), which is crucial for developing and constituting human language as such (Sigel, 2002). Language is the specific tool humans use to organise, negotiate, and communicate their experience of the world, but in order to do so - in the specific symbolic way we do-language itself must also acquire the condition of an object of experience. Language is thus not a purely transparent instrument to denote and communicate things. A flag, for instance, denotes by convention a country, but its very meaning as a symbol requires some conditions of visibility and exhibition to be associated with it. These conditions can be manipulated for different communicative effects (e.g., a flag at half mast). Something similar can be globally attributed to language and verbal signs.

Let us now define "reflexivity" as the general cognitive capacity we have to establish "distance" or "polarisation" between "person and symbolic vehicle", which enables us to experience language and thus open up the possibility of manipulating verbal expression for different purposes. Reflexivity or "reflexive" use of language (Lucy, 1993) entails a specific "attentional" activity by speakers and hearers with regard to linguistic outputs. Moreover, reflexivity is also required for understanding, in Bruner's (1991) sense, linguistic behaviour as an action, i.e., as a kind of strategic and "intentional" behaviour for which intended goals are determinant and meaningful factors. Reflexivity, as a general manifestation of the relationship between semiotic means and users, can be considered to be a specific "design feature of human language" as proposed by Hockett (1960) several decades ago. In other words, this "metacognitive" function is, in our view, not something supplementary, but rather essentially involved in defining the uniqueness of human language. This being the case, the assessment of a specific impairment in the language faculty should include an examination of reflexivity and its means of expression.

Natural metalinguistic abilities are here understood to be the operational aspect of "reflexivity" in language. Reflexivity manifests itself in a variety of techniques that 
contribute to modulating or shaping linguistic expression in different ways and for different purposes. Putting into play natural metalinguistic abilities is a crucial factor for explaining different kinds of adaptive processes carried out by speakers and hearers in specific communicative contexts. They are thus pragmatically aimed, making flexibility possible in both production and understanding of language. In fact, metalinguistic abilities can be considered a prerequisite for the appropriate use of language in context and for functional communication. These abilities are "natural" in the sense that they are developed and put into play without explicit formal instructions, and should not be confused in any case with explicit grammatical knowledge. These abilities count as significant factors for language acquisition by children (Gombert, 1992). To be more exact, the development of these abilities and the development of linguistic structures as such are closely interrelated phenomena.

A certain stage of syntactic and lexical development is, for example, required for putting into play the ability to paraphrase, but in turn this ability and the associated practice is also required for advancing in language acquisition. The metalinguistic ability for paraphrasing permits flexibility in linguistic production but also helps with the understanding of particular expressions. Something similar can be said about our ability to inhibit or postpone speech. Our ability to postpone (i.e., temporarily inhibit) speech is required for regulating conversational interaction, and also for structuring and developing syntax, as so-called "interactional linguistics" (Helasvuo, 2004; Ochs, Schegloff, \& Thompson, 1996) postulates: syntactic structures begin to appear as co-constructions in natural conversational practice (López-García, 1994). Other techniques revealing reflexivity have to do with our ability to report another person's words, with the practice of natural translational or code-switching skills observed in bilingual contexts, with our capacity to modulate voice for different purposes, such as when whispering, or with our ability to inhibit overt expression, as in inner speech practices. Once developed, the techniques and skills revealing reflexivity must still be available for different discursive purposes in adult language. To what extent they are preserved for people with aphasia is the issue under consideration here.

Reflexivity, as previously defined, is so pervasive a phenomenon for language that establishing the specific and complete list of metalinguistic techniques involved in expressing reflexivity would be an unrealistic - and probably unnecessary - task. Metalinguistic techniques are sometimes explicit, as when using language to describe language, and sometimes implicit, as when avoiding the overt expression of a term in a particular situation or even when lying. Metalinguistic techniques can be verbally manifested, as in reported speech, or manifested through non-verbal semiotic procedures, as when using phonic or kinesic gesturing to emphasise an expression. Metalinguistic activity manifests itself both in conscious and preconscious levels of language use. This being the case, the selection of items that can be taken as representative of reflexivity is somewhat challenging, but it should also be tentatively approached when the ultimate research objective justifies it. In our view some recent precedents in the assessment of aphasia contribute to this justification. These precedents have provided us with an initial motivation for exploring how "experience of language" is manifested in people with aphasia and can also suggest the type of metalinguistic techniques relevant for this exploration. Above all, our research is explicitly formulated as a "preliminary study" and the criteria used for the selection of items, as proposed later, remain obviously open to discussion. Metalinguistic activity is always present when using language, both in natural and conventional experimental settings, but our approach attempts to focus attention on the metalinguistic activity itself as a significant factor involved in an impaired linguistic behaviour like aphasia. 


\section{SOME PRECEDENTS}

The classic symptom of anosognosia (Prigatano \& Schacter, 1991) usually manifests itself by affecting specific linguistic items, whose erroneous or inappropriate production goes unnoticed for aphasic individuals. Anosognosia is normally understood as a dichotomous label: this symptom either appears or is absent for a specific linguistic item. Anosognosia undoubtedly indicates a lack of reflexivity. However, impairment of reflexivity, where reflexivity is understood as a cognitive activity that monitors linguistic outputs, clearly goes beyond this specific pathological symptom. It goes beyond the limits of the lexical units, also affecting syntactic abilities, non-verbal semiotic procedures linked to linguistic production, and general discursive and conversational techniques. By including a richer phenomenology within the realm of reflexivity, the use of a procedure for analysing its normal and impaired manifestations in differential terms is required. In other words, reflexivity manifests itself to different degrees, depending on the particular metalinguistic abilities that can be put into play by an individual.

In recent years many research programmes have focused on abilities revealing to what extent monitoring capacities are preserved in people with aphasia. This is the case for research programmes aimed at assessing self-repair linguistic behaviour. Since Milroy and Perkins (1992) this issue has been revisited from different perspectives by Laakso (1997), Damico, Simmons-Mackie, and Wilson (2006), Wilkinson (2007), and others. Co-constructional syntactic abilities also reveal the way monitoring capacities are involved in linguistic production by people with aphasia (Oelschlaeger \& Damico, 1998). In particular, suspended (intentionally interrupted) syntactic constructions are normally observed in natural conversational interaction between aphasic and normal (non-neurologically injured) speakers, which reveals the role of inhibition as a significant component of a general metalinguistic function (Hernández-Sacristán \& Serra-Alegre, 2008). The ability to suspend a syntactic construction or to interpret suspensions made by the conversational partner is associated with a variety of discursive techniques accessible to different degrees for people with aphasia. Inhibition is also an ability associated with code-switching in bilingual speakers. Code-switching, language-mixing, and translational skills in bilingual aphasic speakers have been given some attention in literature (Grosjean, 1985; Muñoz, Marquardt, \& Copeland, 1999; Perecman, 1984). Penn, Frankel, Watermeyer, and Russell (2010) observed the advantage of bilingualism in preserving the executive function by comparing abilities in word definition by bilingual and monolingual aphasic speakers. Word definition is a particular case of paraphrastic ability. It is a metalinguistic technique also present in circumlocutions. The therapeutic effects of a circumlocution-based intervention programme for aphasia has been assessed by Francis, Clark, and Humphrey, 2002. Paraphrastic ability is involved in different discursive techniques of reported speech that, according to Hengst, Frame, Neuman-Stritzel, and Gannaway (2005), are preserved differently in people with aphasia. Ulatowska, Reyes, Santos, and Worle (2011) have recently considered some clinical implications of reported speech for aphasic individuals. The accesibility of specific units that monitor conversational interaction, i.e., discourse markers, have also been explored in people with aphasia (Gallardo Paúls \& Marín-Jordà, 2005; Pietrosemoli, Vera, González Valera, \& Coutín Churchman, 2005; Simmons-Mackie, Elman, Holland, \& Damico, 2007). Without intending to be exhaustive in our review of previous literature, we can ultimately refer to phonic (voicebased) and kinesic (body-based) gestures as a relevant component of our capacity to 
modulate and/or interpret linguistic expression. Phonic and kinesic gestures can thus be considered to be an expression of reflexivity. As for other manifestations of reflexivity, gesturing appears to be closely linked to language development and language processing. Kinesic gesturing has recently been considered to be of great interest for both assessment and therapy of aphasia (Marshall, 2006; Power \& Code, 2006; Rose \& Douglas, 2003, 2008).

\section{AIMS OF THE PAPER}

In our view, although the aforementioned techniques and skills have been studied in aphasiology independently, they should also be dealt with in a combined way. They are all different manifestations of reflexivity in our use of language, for which interrelated cognitive processes should be presupposed. It is assumed here that reflexivity and its corresponding cognitive base must always be to some extent primarily affected or secondarily involved in aphasia. The aim of this paper is to provide a preliminary approach to an integrated protocol for the assessment of reflexivity and associated natural metalinguistic abilities in aphasia. Items used in this protocol have been partially suggested by studies such as the ones previously referred to, but they are also derived from an ethnographic corpus-based exploration focusing on metalinguistic abilities as manifested in natural conversational settings by Spanish aphasic speakers. From a therapeutic perspective our procedure will also enable us to suggest a common basis for different treatment programmes, to assess their relative effects in therapy, and to establish the recovery of metalinguistic abilities as a general goal of rehabilitation. The hypotheses of this paper can be summarised as follows:

- Hypothesis 1: A combined exploration of metalinguistic abilities (including the experiential component associated with them) can be justified for assessing aphasia.

- Hypothesis 2: An impairment of metalinguistic abilities is significantly associated with aphasia.

\section{METHOD}

In order to carry out our objectives a protocol that aims to make an overall assessment of metalinguistic abilities in aphasia has been designed: MetAphAs (Metalanguage in Aphasia Assessment). Each item of the MetAphAs protocol has two versions: one of them defines a specific metalinguistic task required from the aphasic individuals (test) (T) and the other a question on the corresponding metalinguistic ability (questionnaire), directed at both the aphasic individual $\left(\mathrm{Q}^{\mathrm{a}}\right)$ and his or her partner $\left(\mathrm{Q}^{\mathrm{p}}\right)$ (or at one of them in some cases). The test aims to evaluate abilities in performing metalinguistic tasks and the questionnaire to explore the way the metalinguistic abilities at hand are taken into account by the aphasic individual and/or his/her partner. The protocol includes 40 items distributed in six sections, which correspond to different aspects of reflexivity. These sections should not be considered as watertight compartments, but rather as areas that partially overlap. The sections define different perspectives of a general metalinguistic function, which (according to Harley et al., 2008, p. 322) embraces "a number of high-level executive functions such as awareness, theory of mind, monitoring, planning, controlled processing, and updating (Bialystok \& Ryan, 1985; Doherty \& Perner, 1998; Gombert, 1992; Karmiloff-Smith, 1986)". 
These metacognitive processes, previous research programmes on aphasia assessment, and a tradition of cross-linguistic studies on the reflexive use of language (Lucy, 1993) have been jointly considered in order to justify the layout of the sections we provide here. Items of the protocol corresponding to each section represent specific metalinguistic abilities that illustrate one particular aspect of reflexivity. Examples of the particular tasks requested of participants for the assessment of specific metalinguistic abilities are given in the Appendix. A data analysis performed previously justified discarding 8 items from an initial 48 -item version of the protocol. Six of these items were aimed at the assessment of natural cross-linguistic or translational abilities (we have only five bilinguals in our sample), and the other two were redundant tasks from a statistical point of view. The aspects of reflexivity considered here are not conceived, at least in this preliminary study, as explanatory factors suitable for a confirmatory factor analysis. As we have said, the sections we provide cannot be thought of as watertight compartments. There are probably also hierarchical relationships between the different aspects of reflexivity under examination in this paper, which makes it problematic to interpret the linear combination of the corresponding loadings. An exploratory analysis of main components reveals that six common factors explain the $67.99 \%$ of the variance in our data, but, as expected, only partial correspondences are observed between these factors and the six aspects of reflexivity considered here. Further research, with a greater number of participants, is obviously required to justify the distribution of aspects of reflexivity not only in theoretical but also in statistical terms. The sections and the items finally included in our protocol are as follows.

\section{Protocol description: Aspects of reflexivity}

Section I. Inhibited, inner, and deferred speech. A crucial, and probably foundational, feature defining the specificity of verbal human behaviour (HernándezSacristán, 2006; Hurford, 2004) has to do with our capacity of inhibiting external vocalisation or, to be more exact, our capacity to intentionally switch from an external to an internal use of language, which eventually also enables us to defer our intended expression. The pragmatic and experiential components of this ability are clearly interrelated. Being capable of inhibiting verbal production for different purposes entails increasing our attention to language (Frankel \& Penn 2007), and assigning language its role as a conveyer of an intentional communicative action. To assess this general ability a variety of linguistic techniques or skills can be explored: some of them are present in conventional experimental tests (for example, deferring an answer); others are involved in some natural linguistic practices. See Geva, Bennett, Warburton, and Patterson (2011) for a more detailed discussion about inner speech abilities in aphasia. The following items have been chosen in our protocol to represent the aspect of reflexivity we identify as inhibited-inner-deferred speech:

1. Monological activity

2. Verbalisations supporting everyday activities

3. Whispering

4. Silent reading

5. Deferred use of language (deferred answer)

6. Deferred use of language (deferred description) 
Section II. Control of concurrent semiotic procedures. Natural use of language usually involves the combination of specific verbal expression with other semiotic procedures and particularly with both kinesic and phonic gestures. Gesturing has an important role in scaffolding, planning, and structuring verbal expression, or occasionally in compensating for a verbal deficit by preserving the communicative purposes. These effects of gesturing can be understood as particular manifestations of the executive function when applied to verbal behaviour, i.e., as a "natural metalanguage". The Growth Point Theory (McNeill \& Duncan, 2000) has focused on concurrent gesturing as a very relevant factor for language development but, as previously mentioned, this issue has also recently been a recurrent topic of research in aphasiology. Melodic intonation can be included here by considering its supporting role for the retrieval of words and for sentence production (and comprehension). Discourse markers share with concurrent gesturing the same aforementioned effects on verbal expression. They normally appear as detached from the basic syntactic plan, i.e., on a "meta-syntactic" level. The following items represent the aspect of reflexivity under consideration here:

7. Discursive markers

8. Gesturing concurrent with verbal activity

9. Melodic intonation

10. Phonic gesture and emotional content expressions

11. Conventional intonation

Section III. Paraphrastic abilities and associated phenomena. No special argument is required for including paraphrastic abilities as a manifestation of reflexivity in language. Saying things with different words has both the role of clarifying meanings and of adapting discourse to circumstances. Paraphrastic ability is also strategically put into play to avoid difficulties in the retrieval of specific lexical items. Additionally, two situations can be included here for examination: the tip-of-the-tongue (TOT) phenomenon and the phenomenon of paraphasia. The TOT phenomenon entails, in fact, suspension of a proper paraphrastic strategy, but it is normally associated with inner speech activity involving a mental listing of lexical items around a lexical gap: "saying with different words" acquires here the quality of "talking around a word". Paraphasias are also considered, but only to assess the degree to which they arouse some comments (i.e., explicit metalinguistic activity) around a perceived lexical mistake. Items in our protocol exemplifying paraphrastic abilities and associated phenomena are as follows:

12. Definition of terms naming particular objects

13. Definition of abstract terms

14. Circumlocutions

15. Tip of the tongue phenomenon

16. Paraphasias

Section IV. Reported speech and associated phenomena. Reported speech is a natural metalinguistic ability that usually combines deferred use of language and paraphrastic ability. The aspects of reflexivity corresponding to sections I and III are to some extent blended here to serve the role of the speaker as a communicative mediator. Reported speech is a basic manifestation of the interrelationship between verbal 
and social abilities. The aspect of reflexivity corresponding to section II can also be present in this section given the fact that reported speech is usually associated - in natural conversational settings - with the imitation of the kinesic and phonic gestures of the speaker whose words are being reported. Reported speech is illustrated in our protocol with the following items:
17. Reported speech
18. Reported speech and phonic gesturing
19. Voice imitation
20. Reporting a story

Section V. General monitoring abilities and contextualisation cues. This dimension of reflexivity includes both our general capacity to monitor the linguistic outputs by taking account of them as perceived objects and the pragmatic functions associated with this capacity, i.e., adaptive strategies in the use of language. Monitoring abilities have been a common independent assessment goal, but in our view their assessment should be linked with their functions in different everyday speech situations. Monitoring a linguistic expression and adapting it for different communicative purposes or situations are two sides of the same coin. The following items have been selected in our protocol to illustrate this issue:

21. Monitoring syllables: separating syllables in a word

22. Monitoring phrase structure: sense stress for emphasis

23. Monitoring syllables with the support of gesturing

24. Ways of saying in context

25. Monochannel communication ability

26. Communication ability with absent addressee

27. Self-correction ability

28. Hetero-correction ability

29. Assessing another's words

30. Ability to fill in lexical gaps

Section VI. Displaced use of language and Theory of Mind (TOM) phenomena. Displaced use of language involves a capacity to speak about things not present in the immediate vicinity of the speaking act. The speaker moves along the coordinates of communication in spatial or temporal terms, establishing distance from the origin of these coordinates: i.e., the I, the Here, and the Now (Hockett, 1960). This movement involves abstraction or abstract attitude in managing language (a "distal” position, according to Hernández-Sacristán, Rosell-Clari, \& MacDonald, 2011). Moreover, "displacement" along coordinates must be considered as a precondition for the ability to actually "change" coordinates of communication by assuming the point of view of a hearer, i.e., for the ability to develop a Theory of Mind (BaronCohen, Trager-Flusberg, \& Cohen, 2000) and to control the inter-subjective dimension involved in every communicative action. "Displacement" and "change" of communication coordinates defines a specific domain of the executive function involved in linguistic behaviour. The following items illustrate this issue in our protocol:

31. Describing an object or situation not present

32. Remembering recent past events

33. Remembering remote past events 
34. Anticipating future events

35. Describing a scene

36. Ability to contradict and/or find antonyms

37. Emotion reading

38. Fictional use of language

39. Ability to lie

40. Expressing sarcasm

\section{Participants}

A total of 21 aphasic Spanish-speaking individuals participated in the study, 14 men and 7 women, whose age range was 48-82 (mean of 65.42 and standard deviation of 11.01). They were referred to us for study by the neurological services of different private and public hospitals from the city of Valencia (Spain). The participants were all literate people, although their backgrounds varied from professionals with university education to manual workers with more basic education, including office workers, housewives, and others. Items of the protocol were formulated using everyday Spanish expressions and avoiding technical terms. In this way basic comprehension for all participants, both aphasic people and partners, was ensured. The partners were all direct relatives of the aphasic participants, e.g., wife, husband, daughter, or son, whose age range was 24-70. The specific questionnaire directed at the partners was designed to eventually compensate for difficulties in eliciting information from the aphasic participants. Type and severity of aphasia has been assessed by means of the Spanish version of the Boston Diagnostic Aphasia Examination (BDAE; Goodglass \& Kaplan, 1983, 1998), which was administered to all aphasic participants. There is a variety of aphasia types represented, with motor aphasia being especially prominent. We examined 12 people with dominant motor aphasia, 5 having dominant sensitive aphasia and 4 with residual anomic aphasia. The five steps in the scale of severity are represented in our sample, although most of the aphasic participants, eight of them, manifest moderate severity. The scale (0-1-2-3-4) categorised the participants as follows: three very serious, three serious, four severe, eight moderate, and three minor cases. All participants were at least 1 year post-stroke. They had a varied aetiology, although ischaemic or haemorrhagic strokes were dominant. Age, sex, type, severity of aphasia, as well as aetiology are shown inTable 1.

\section{Procedure}

The MetAphAs protocol was administered in the following way to individuals previously assessed by means of the BDAE. All 21 aphasic participants were assessed by means of the MetAphAs test. The two MetAphAs questionnaires were administered in a single session 1 or 2 weeks later. As a general rule, the items of the questionnaire, which had been previously directed towards the aphasic individual, were now directed at the partner in order to obtain, if possible, a complementary view or indeed for filling occasional gaps in the information obtained from the aphasic individual. However, administration of the questionnaires was partial due to personal or clinical reasons. In 6 of the low to moderate cases the aphasic individual was alone in the interview, which is why the questionnaire directed to the partner $\left(\mathrm{Q}^{\mathrm{p}}\right)$ was only administered in 15 cases. In 5 of the very serious to serious cases eliciting declarative knowledge from the aphasic individual was problematic, so 
TABLE 1

Aphasic participants

\begin{tabular}{|c|c|c|c|c|c|}
\hline Participant & Age & $\operatorname{Sex}$ & Aphasia type & Severity & Aetiology \\
\hline ASSMG & 67 & Male & Sensory aphasia & 0 & $\begin{array}{l}\text { Left parietal occipital cerebral } \\
\text { haematoma }\end{array}$ \\
\hline ASSTM & 74 & Female & $\begin{array}{l}\text { Transcortical sensory } \\
\text { aphasia }\end{array}$ & 3 & $\begin{array}{l}\text { Left sylvian ischaemic stroke, due to left } \\
\text { carotid thrombosis }\end{array}$ \\
\hline ASSTS & 71 & Male & $\begin{array}{l}\text { Transcortical sensory } \\
\text { aphasia }\end{array}$ & 2 & $\begin{array}{l}\text { Extensive left temporal parietal ischaemic } \\
\text { stroke }\end{array}$ \\
\hline ВРМММ & 68 & Male & $\begin{array}{l}\text { Motor-mixed } \\
\text { aphasia }\end{array}$ & 3 & Left temporal ischaemic stroke \\
\hline CSMMM & 70 & Male & $\begin{array}{l}\text { Motor-mixed } \\
\text { aphasia }\end{array}$ & 3 & $\begin{array}{l}\text { Left sylvian ischaemic thrombotic stroke } \\
\text { of hypertensive origin }\end{array}$ \\
\hline DTMMM & 82 & Female & $\begin{array}{l}\text { Motor-mixed } \\
\text { aphasia }\end{array}$ & 3 & Left temporal parietal haematoma \\
\hline EMMMS & 75 & Male & $\begin{array}{l}\text { Motor-mixed } \\
\text { aphasia }\end{array}$ & 2 & Left anterior sylvian embolism \\
\hline EASG & 77 & Female & Sensory aphasia & 1 & $\begin{array}{l}\text { Extensive left temporal parietal ischaemic } \\
\text { stroke }\end{array}$ \\
\hline FGMTM & 72 & Female & $\begin{array}{l}\text { Transcortical motor } \\
\text { aphasia }\end{array}$ & 3 & Multiple sylvian ischaemic stroke \\
\hline JHAL & 46 & Male & Anomic aphasia & 4 & Left sylvian ischaemic stroke \\
\hline JMMMG & 59 & Male & $\begin{array}{l}\text { Motor-mixed } \\
\text { aphasia }\end{array}$ & 1 & Left sylvian ischaemic thrombotic stroke \\
\hline JVMMG & 69 & Male & Motor aphasia & 0 & $\begin{array}{l}\text { Left parietal intraparenchymal } \\
\text { hemorrhage }\end{array}$ \\
\hline MLAM & 58 & Female & Anomic aphasia & 3 & $\begin{array}{l}\text { Left sylvian ischemic thrombotic stroke of } \\
\text { hypertensive origin }\end{array}$ \\
\hline MMAL & 48 & Female & Anomic aphasia & 4 & Left sylvian ischaemic stroke \\
\hline MMMTS & 51 & Male & $\begin{array}{l}\text { Transcortical motor } \\
\text { aphasia }\end{array}$ & 2 & $\begin{array}{l}\text { Ischaemic stroke in left middle and } \\
\text { anterior cerebral arteries }\end{array}$ \\
\hline MSMMG & 80 & Female & Motor aphasia & 0 & Left sylvian embolism \\
\hline PPMMG & 51 & Male & $\begin{array}{l}\text { Motor-mixed } \\
\text { aphasia }\end{array}$ & 1 & Left sylvian ischaemic stroke \\
\hline RSMMM & 75 & Male & $\begin{array}{l}\text { Motor-mixed } \\
\text { aphasia }\end{array}$ & 3 & Left frontal ischaemic stroke \\
\hline VNMMS & 65 & Male & $\begin{array}{l}\text { Motor-mixed } \\
\text { aphasia }\end{array}$ & 2 & Left frontal cerebral haematoma \\
\hline VRAL & 50 & Male & Anomic aphasia & 4 & Left sylvian ischaemic stroke \\
\hline VRMSM & 66 & Male & $\begin{array}{l}\text { Sensory-mixed } \\
\text { aphasia }\end{array}$ & 3 & Left middle artery ischaemic stroke \\
\hline
\end{tabular}

the questionnaire directed to the aphasic individual $\left(\mathrm{Q}^{\mathrm{a}}\right)$ was only administered in 16 cases. The latter circumstance is a logical consequence of adapting the administration of the MetAphAs protocol to the "natural" context-including personal and clinical factors - in which data can be elicited from people with aphasia. This fact does not seriously affect our conclusions. Our scores are based on a 5-point scale for assessing efficiency (from poor to good) in resolving items in the test (with specific criteria for each item). A 5-point qualitative scale was also used for assessing items of the questionnaire on metalinguistic abilities available. Data obtained from BDAE and MetAphAs Test and Questionnaires were transferred to the Microsoft Excel 2007 software program and statistically analysed using the PASW Statistics 18 software program. 


\section{RESULTS}

In order to prove inter-rater reliability the scores assigned by two clinicians to five of the participants were compared. The two clinicians, assigning scores independently, were simultaneously present at the assessment sessions. A significant correlation value of .89 was obtained. Moreover, in order to prove internal consistency of MetAphAs, Cronbach's alpha coefficient was applied to the scores obtained by all participants in the 40 items of the test and the questionnaires (with the limitations previously mentioned regarding the questionnaires) (Table 2).

As the values of the Cronbach's alpha coefficient show, the MetAphAs test and questionnaires can be considered highly reliable, at least when taking into consideration our preliminary data. The internal consistency of the MetAphAs allows us to confirm that a combined exploration of metalinguistic abilities, like the ones selected in this protocol, can be justified from a psychometric point of view when assessing aphasia.

Pearson's coefficients used to correlate BDAE global scores with the scores from MetAphAs test and questionnaires enable us to prove the validity (concurrent validity) of MetAphAs. The correlation coefficients obtained (Table 3) are all positive, high, and statistically significant $(p<.05)$.

Although the correlation coefficients are positive and high, there are significant average differences between scores from the MetAphAs test, the two MetAphAs questionnaires and the BDAE global scores, $F(3,67)=33.608 ; p=.001$. Post-hoc analysis reveals that these significant differences are always due to the BDAE (Table 4). Thus we are clearly dealing with two different instruments for assessing aphasia here.

When comparing global scores from the MetAphAs test and questionnaires there are no statistically significant differences. There are, however, significant differences when comparing scores obtained in the test and the two questionnaires for the following items: item $7, F(2,48)=3.836 ; p=.028$; item $9, F(2,48)=8.173 ; p=.001$; item $13, F(2,48)=3.473 ; p=.039$; item $15, F(2,48)=5.158 ; p=.009$; item 18 , $F(2,48)=8.172 ; p=.001 ;$ item $30, F(2,48)=8.912 ; p=.001$; item $37, F(2,48)=$

TABLE 2

Reliability of MetAphAs

\begin{tabular}{lc}
\hline & Cronbach's alpha coefficient \\
\hline MetAphAs Test & .973 \\
MetAphAs Qp & .916 \\
MetAphAs Q $^{\mathrm{a}}$ & .918 \\
\hline
\end{tabular}

TABLE 3

MetAphAs/BDAE correlation coefficients

\begin{tabular}{lcccc}
\hline & MetAphAs $Q^{a}$ & MetAphAs $Q^{p}$ & MetAphAs Test & BDAE \\
\hline MetAphAs Q $^{\mathrm{a}}$ & 1 & $.660^{*}$ & $.655^{*}$ & $.744^{*}$ \\
MetAphAs Q & $.660^{*}$ & 1 & $.929^{*}$ & $.871^{*}$ \\
MetAphAs Test & $.655^{*}$ & $.929^{*}$ & 1 & $.793^{*}$ \\
BDAE & $.744^{*}$ & $.871^{*}$ & $.793^{*}$ & 1 \\
\hline
\end{tabular}

${ }^{*} p<.05$. 
TABLE 4

Post-hoc analysis BDAE and MetAphAs

\begin{tabular}{|c|c|c|}
\hline & Average differences & Significance \\
\hline BDAE/MetAphAs $Q^{a}$ & 197.437 & $p<.001$ \\
\hline BDAE / MetAphAs $Q^{p}$ & 208.732 & $p<.001$ \\
\hline BDAE / MetAphAs Test & 204.946 & $p<.001$ \\
\hline
\end{tabular}

Tukey HSD.

$16.520 ; p=.001$. As expected, some differences can be observed between the ability to perform a task by the aphasic participant (MetAphAs test), and the capacity to take account of this ability and comment on it by the aphasic participant or his/her partner (MetAphAs $\mathrm{Q}^{\mathrm{a}}$ and $\mathrm{Q}^{\mathrm{p}}$ ). Post-hoc analysis (Tukey HSD) confirms that, for the above-mentioned items, significant differences are obtained only when comparing MetAphAs test with questionnaires, but not when comparing questionnaires with each other. The concordance between questionnaires is probably due to the fact that they were administered in a single session with both aphasic participant and his/her partner present.

\section{Severity and type of aphasia}

Although our battery is not conceived as a differential diagnosis tool for aphasia, the MetAphAs test and questionnaires show high sensitivity to the severity of aphasia (Table 5).

As for the type of aphasia, both the MetAphAs test and the MetAphAs $\mathrm{Q}^{\mathrm{a}}$ show significant differences, but the MetAphAs $\mathrm{Q}^{\mathrm{p}}$ does not (Table 6).

The fact that the partner's perspective is significantly sensitive to severity but not to aphasia type probably requires a more comprehensive examination. It does provide, in any case, a meaningful insight into the way the partner's role can be incorporated as a recovery factor in aphasia.

TABLE 5

Severity of aphasia and MetAphAs

\begin{tabular}{lcc}
\hline & $F$ & $p$-value \\
\hline MetAphAs Q $^{\mathrm{a}}$ & $F(3,12)=22.062$ & $<.001$ \\
MetAphAs Q $^{\mathrm{p}}$ & $F(4,10)=14.335$ & $\leq .001$ \\
MetAphAs Test & $F(4,16)=14.004$ & $<.001$ \\
\hline
\end{tabular}

TABLE 6

Aphasia type and MetAphAs

\begin{tabular}{lrr}
\hline & $F$ & $p$-value \\
\hline MetAphAs Q $^{\text {a }}$ & $F(6,9)=10.158$ & $<.001$ \\
MetAphAs Q $^{\text {p }}$ & $F(5,9)=1.684$ & $\leq .244$ \\
MetAphAs Test & $F(6,14)=5.133$ & $\leq .006$ \\
\hline
\end{tabular}




\section{DISCUSSION AND CONCLUSIONS}

The results of this preliminary study are conclusive enough to justify an exploration of metalinguistic abilities in aphasia, as previously defined. The internal consistency of the results supports the proposal to treat the list of items under consideration in this paper as an integrated object of assessment. As mentioned above, the high values of Cronbach's alpha coefficient clearly demonstrate this consistency and enable us to support hypothesis 1 of this paper, i.e., that a combined exploration of metalinguistic abilities can be justified for assessing aphasia. Our results permit us to think about an explanatory factor shared, in our view, by some previous research programmes for the assessment of aphasia. We know this factor as "reflexivity", which refers to the general capacity of experiencing language and thus manipulating language for different purposes. Reflexivity is not simply one component among others of human verbal behaviour. Reflexivity and the associated metalinguistic abilities are necessarily involved in the processes by which a language is constructed and as a factor that transforms language into a dynamic, expert system: a system with a self-regulating capacity and sensitivity to external communicative context and demands.

It is thus worth noting here that the cognitive domain explored by means of this protocol is not one that is only peripherally related with verbal behaviour (as manifested in natural contexts), but rather one that plays a central role as a specific component of this behaviour (no less than some formal - supposedly universal-properties of syntax). Natural metalinguistic abilities are in fact a manifestation of our general linguistic abilities. Putting natural metalinguistic abilities into play requires specific linguistic resources to be at hand. This being the case, these abilities will be intermingled and affected to some extent in any linguistic impairment, particularly when this impairment is a language-selective one, as in the case of aphasia. In short, we are assessing language as a natural human capacity (even in a specific way) when focusing our attention on reflexivity and metalinguistic abilities.

There is no contradiction here when considering that the cognitive domain being explored in this paper corresponds more to a functional level of integration blending executive function and verbal behaviour than to a specific neurological structure. By accepting assumptions of distributive models, looking for specificity in language probably means looking for a "specific intersection" or interrelationship of cognitive domains. As a consequence, specificity of a central linguistic impairment must be basically (although not exclusively) assessed as a deficit affecting the functional integration of these domains, which broadly speaking characterises high psychological processes like those involved in verbal behaviour. Disassociating cognitive domains involved in verbal behaviour will not always be the best method for identifying the specificity of this behaviour.

This was our basic assumption when focusing our research objective on assessing natural metalinguistic abilities in aphasia, i.e., on assessing not performance of executive functions considered as independent from linguistic behaviour (Purdy, 2002) but the specific linguistic implementation of executive functions. Previous research focusing on the assessment of executive functions in people with aphasia reveals no significant correlations with linguistic impairments (Fridriksson, Nettles, Davis, Morrow, \& Montgomery, 2006; Glosser \& Goodglass, 1990; Helm-Estabrooks, Bayles, Ramage, \& Bryant, 1995). The neurological correlates normally assigned to the executive functions are not necessarily affected in classic aphasic syndromes, which may explain this fact. However, Ardila's (2010) proposal uses the label "dysexecutive" 
aphasia for identifying an aphasic syndrome where prefrontal areas or a more complex distributed neurological basis are involved. Classic syndromes such as Broca's and Wernicke's aphasia are supposedly free of a primary dysexecutive factor, but Ardila's proposal includes a thorough consideration of the role Broca's area plays as the neurological basis for inner speech ability, closely linked, as previously mentioned, to inhibition, i.e., a central issue in the realm of the executive function (McDonald \& Van Sommers, 1993; Ylvisaker \& Szekeres, 1989). Things must, in any case, be rethought when exploring executive functions as expressed and implemented in verbal (or concurrent with verbal) tasks, i.e., when exploring reflexivity, meaning the cognitive domain where executive functions and verbal behaviour are functionally interrelated and mixed.

Our results support hypothesis 2 of this paper, i.e., that an impairment of metalinguistic abilities and reflexivity is significantly associated with aphasia, as is shown by the sensitivity of our protocol to both severity of aphasia and aphasia type. No relation of cause and effect between aphasia and impairment of metalinguistic abilities can be established by considering the results of this preliminary research. To go further in this direction, additional research on the neurological basis of metalinguistic abilities is required, i.e., on the way the aforementioned blending of executive functions and verbal behaviour is neurologically implemented. This objective is clearly beyond the aims of this paper.

There is an additional reason for exploring natural metalinguistic abilities in aphasia. Taking a reflexive account of language and recovering linguistic skills can be considered to be related aims in aphasia rehabilitation. Without explicitly mentioning "reflexivity" or "metalinguistic abilities" as therapeutic goals, language therapy usually aims to increase and improve the strategic and monitoring capacities that control language use. Assessment of the remaining manifestations of reflexivity, i.e., of the preserved metalinguistic abilities, can also provide a required baseline for the therapeutic work. As our data also reveal, working on metalinguisitc abilities means, moreover, focusing on an experiential component significantly associated with verbal behaviour. In this way an active role of the affected individuals in the recovery process can be substantiated by considering - as assumed nowadays in clinical pragmatics (Gallardo Paúls, 2005; Simmons-Mackie, Raymer, Armstrong, Holland, \& Cherney, 2010; Wilkinson, Bryan, Lock, \& Sage, 2011) - that not only people with aphasia but also their partners come under the label of "affected individuals".

Manuscript received 10 June 2011

Manuscript accepted 5 October 2011

First published online 30 November 2011

\section{REFERENCES}

Ardila, A. (2010). A proposed reinterpretation and reclassification of aphasic syndromes. Aphasiology, 24(3), 363-394.

Barkley, R. A. (1997). Behavioural inhibition, sustained attention, and executive functions: Constructing a unifying theory of ADHD. Psychological Bulletin, 121, 65-94.

Barkley, R. A. (2001). The executive functions and self-regulation: An evolutionary neuropsychological perspective. Neuropsychological Review, 11(1), 1-29.

Baron-Cohen, S., Tager-Flusberg, H., \& Cohen, D. J. (Eds.). (2000). Understanding other minds. Perspectives from developmental cognitive neuroscience. Oxford, UK: Oxford University Press.

Bialystok, E. \& Ryan, E. B. (1985). Toward a definition of metalinguistic skill. Merill-Palmer Quarterly, 31, 229-251. 
Bruner, J. (1991). Acts of meaning. Cambridge, MA: Harvard University Press.

Damico, J. S., Simmons-Mackie, N., \& Wilson, B. (2006). The negotiation of intelligibility in an aphasic dyad. Clinical Linguistics and Phonetics, 20(7-8), 599-605.

Doherty, M. J., \& Perner, J. (1998). Metalinguistic awareness and theory of mind: Just two words for the same thing? Cognitive Development, 13, 279-305.

Francis, D. R., Clark, N., \& Humphrey, G. W. (2002). Circumlocution-induced naming. A treatment for effecting generalisation in anomia? Aphasiology, 16(3), 234-259.

Frankel, T., \& Penn, C. (2007). Perseveration and conversation in TBI: Response to pharmacological intervention, Aphasiology, 21(10/11), 1039-1078.

Fridriksson, J., Nettles, C., Davis, M., Morrow, L., \& Montgomery, A. (2006). Functional communication and executive function in aphasia. Clinical Linguistics and Phonetics, 20(6), 401-410.

Gallardo-Paúls, B. (2005). Afasia y conversación. Valencia, Spain: Tirant lo Blanch.

Gallardo-Paúls, B., \& Marín Jordà, M. J. (2005). Marcadores discursivos procedentes de verbos perceptivos en el discurso afásico. Revista de Investigación Lingüística, 8, 53-94.

Geva, S., Bennett, S., Warburton, E. A., \& Patterson, K. (2011). Discrepancy between inner and overt speech: Implications for post-stroke aphasia and normal language processing. Aphasiology, 25(3), 323-343.

Glosser, G., \& Goodglass, H. (1990). Disorders in executive functions among aphasic and other brain damage patients. Journal of Clinical and Experimental Neuropsychology, 12(4), 485-501.

Gombert, J. E. (1992). Metalinguistic development. Hertfordshire, UK: Harvester Wheatsheaf.

Goodglass, H., \& Kaplan, E. (1983). Boston Diagnostic Aphasia Examination. Philadelphia, PA: Lea \& Febiger.

Goodglass, H., \& Kaplan, E. (1998). Evaluación de la afasia y de los trastornos relacionados. Madrid: Panamericana.

Grosjean, F. (1985). Polyglot aphasics and language mixing: A comment on Perecman (1984). Brain and Language, 26, 349-355.

Harley, T. A., Jessiman, L. J., MacAndrew, S. B. G., \& Astell, A. (2008). I don't know what I know: Evidence of preserved semantic knowledge but impaired metalinguistic knowledge in adults with probable Alzheimer's disease. Aphasiology, 22(3), 321-335.

Helasvuo, M. J. (2004). Shared syntax: The grammar of co-constructions. Journal of Pragmatics, 36, $1315-1336$.

Helm-Estabrooks, N., Bayles, K., Ramage, A., \& Bryant, S. (1995). Relationship between cognitive performance and aphasia severity, age, and education: Females versus males. Brain and Language, 51, 139-141.

Hengst, J. A., Frame, S. R., Neuman-Stritzel, T., \& Gannaway, R. (2005). Using others' words: Conversational use of reported speech by individuals with aphasia and their communication partners. Journal of Speech, Language, and Hearing Research, 48(1), 137-157.

Hernández-Sacristán, C. (2006). Inhibición y Lenguaje. A Propósito de la Afasia y la Experiencia del Decir. Madrid, Spain: Biblioteca Nueva.

Hernández-Sacristán, C., Rosell-Clari, V., \& MacDonald, J. E., (2011). Proximal and distal. Rethinking linguistic form and use for clinical purposes. Clinical Linguistics \& Phonetics, 25(1), 37-52.

Hernández-Sacristán, C., \& Serra-Alegre, E. (2008). Construcciones suspendidas y gestión del turno conversacional en la evaluación de la afasia. Pragmalingüística, 15-16, 112-132.

Hockett, C. F. (1960). The origin of speech. Scientific American, 203, 88-96.

Hurford, J. (2004). Language beyond our grasp: What mirror neurons can, and cannot do, for the evolution of language. In D. K. Oller \& K. Griebel (Eds.), Evolution of communication systems: A comparative approach (pp. 297-313). Cambridge, MA: MIT Press.

Karmiloff-Smith, A. (1986). From meta-processes to conscious access: Evidence from children's metalinguistic and repair data. Cognition, 23, 95-147.

Laakso, M. (1997). Self-initiated repair by fluent aphasic speakers in conversation. Helsinki, Finland: Finnish Literature Society.

López-García, A. (1994). Gramática del Español I: La oración compuesta. Madrid, Spain: Arco Libros.

Lucy, J. A. (Ed.). (1993). Reflexive language. Reported speech and metapragmatics. Cambridge, UK: Cambridge University Press.

Marshall, J. (2006). The roles of gesture in aphasia therapy. Advances in Speech-Language Pathology, 8, 1-5.

McDonald, S., \& Van Sommers, P. (1993). Pragmatic language skills alter closed head injury: Ability to negotiate requests. Cognitive Neuropsychology, 10, 297-315. 
McNeill, D., \& Duncan, S. D. (2000). Growth points in thinking-for-speaking. In D. MacNeill (Ed.), Language and gesture (pp. 141-161). Cambridge, UK: Cambridge University Press.

Milroy, L., \& Perkins, L. (1992). Repair strategies in aphasic discourse; towards a collaborative model. Clinical Linguistics and Phonetics, 6(1-2), 27-40.

Muñoz, M. L., Marquardt, T. P., \& Copeland, G. (1999). A comparison of the codeswitching patterns of aphasic and neurologically normal bilingual speakers of English and Spanish. Brain and Language, 66(1), 249-274.

Ochs, E. A., Schegloff, E., \& Thompson S. A. (Eds.). (1996). Interaction and grammar. Cambridge, UK: Cambridge University Press.

Oelschlaeger, M. L., \& Damico, J. D. (1998). Joint productions as a conversational strategy in aphasia. Clinical Linguistics and Phonetics, 12(6), 459-480.

Penn, C., Frankel, T., Watermeyer, J., \& Russell, N. (2010). Executive function and conversational strategies in bilingual aphasia. Aphasiology 24(2), 288-308.

Perecman, E. (1984). Spontaneous translation and language mixing in a polyglot aphasic. Brain and Language, 23, 43-63.

Pietrosemoli, L., Vera, M., González Valera, S., \& Coutin Churchman, P. (2005). Marcadores discursivos en hablantes sanos y afásicos: el caso especial de "y". Boletín de Lingüística, 17, 25-30.

Power, E., \& Code, C. (2006). Waving not downing: Utilising gesture in the treatment of aphasia. International Journal of Speech-Language Pathology, 8(2), 115-119.

Prigatano, G. P., \& Schacter, D. L. (1991). Awareness of deficit after brain injury: Clinical and theoretical issues. Oxford, UK: Oxford Univrsity Press.

Purdy, M. (2002). Executive function ability in persons with aphasia. Aphasiology, 16(4/5/6), 549-557.

Rose, M., \& Douglas, J. (2003). Limb apraxia, pantomime, and lexical gesture in aphasic speakers: Preliminary findings. Aphasiology, 17(5), 453-464.

Rose, M., \& Douglas, J. (2008). Treating a semantic word production with verbal and gestures methods. Aphasiology, 22(1), 20-41.

Sigel, I. E. (2002). The psychological distancing model: A study of the socialization of cognition. Culture \& Psychology, 8(2), 189-214.

Simmons-Mackie, N., Elman, R. J., Holland, A., \& Damico J. (2007). Management of discourse in group therapy for aphasia. Topics in Language Disorders, 27(1), 5-23.

Simmons-Mackie, N., Raymer, A., Armstrong, E., Holland, A., \& Cherney, L. R. (2010). Communication partner training in aphasia: A systematic review. Archives of Physical Medicine and Rehabilitation, 91(12), 1814-1837.

Ulatowska, H. K., Reyes, B. A., Santos, T. O., \& Worle, C. (2011). Stroke narratives in aphasia: The role of reported speech. Aphasiology, 25(1), 93-105.

Werner, H., \& Kaplan, B. (1978). The nature of symbol formation and its role in cognition: Theoretical considerations. In S. S. Barten \& M. B. Franklin (Eds.), Developmental processes: Heinz Werner's selected writings, Vol. 2: Cognition, language, and symbolization (pp. 471-485). New York, NY: International Universities Press.

Wilkinson, R. (2007). Managing linguistic incompetence as a delicate issue in aphasic talk-in-interaction: On the use of laugther in prolonged repair sequences. Journal of Pragmatics, 39, 542-569.

Wilkinson, R., Bryan, K., Lock, S., \& Sage, K. (2011). Interaction-focused intervention for couples where one partner has aphasia: Facilitating the collaborative production of topic initiating turns. International Journal of Speech-Language Pathology, 13(1), 74-87.

Ylvisaker, M., \& Szekeres, S. F. (1989). Metacognitive and executive impairments in head-injured children and adults. Topics in Language Disorders, 9(2), 34-49. 


\section{APPENDIX}

\section{Questionnaire and test (Q-T)}

We provide here a slightly modified English version of the original Spanish, by summarising the content of the items. The administered protocol consists of three different tools: a questionnaire directed at the aphasic individual $\left(\mathrm{Q}^{\mathrm{a}}\right)$, a questionnaire directed at his/her partner $\left(\mathrm{Q}^{\mathrm{p}}\right)$, and a test directed at the aphasic individual $(\mathrm{T})$. The protocol contains graphic support material and specific assessment criteria for each item.

\section{Inner, inhibited, and deferred speech}

1. Monological activity

Q- Thinking aloud is something people usually do. Do you (Does he/she) plan your (his/her) activities for the day or remember something by thinking aloud?

T- Thinking aloud is something people usually do. Try to describe or imitate this situation.

2. Verbalisations supporting everyday activities

Q- When performing some activity, for example preparing a meal, doing housework, etc., do you (does he/she) talk out loud while doing this? Does it help you (Do you think it helps him/her)?

T- Try to describe or imitate this kind of action: preparing a meal, doing housework.

3. Whispering

Q- Do you (he/she) whisper or speak in an undertone when necessary? [clinician is whispering when formulating this question]

T- Please, tell me a little secret. I don't know your age. How old are you? [clinician is whispering when requesting this task, and coordinated whispering is expected from the individual under examination]

4. Silent reading

Q- If you (he/she) can read, do you (does he/she) also read silently to your(his-/her-) self?

T- Would you like to read this to yourself? [a question follows, checking comprehension of a Spanish ten-line text under this reading condition]

5. Deferred use of language (deferred answer)

Q- Does taking a little time before answering a question help you (him/her) sometimes?

T- I want to know when your birthday is and where you were born, but don't tell me right now, but when I ask you [clinician says "now"] (15 seconds)

6. Deferred use of language (deferred description)

Q- Does taking a little time for thinking before describing something or telling a story help you (him/her) sometimes?

T- What is your favourite meal? Can you describe how to prepare it? But don't tell me right now, but when I ask you [clinician says "now"] (20 seconds)

\section{Control of concurrent semiotic procedures}

7. Discursive markers

Q- Do you (Does he/she) use some word-tags or pet expressions when saying something? Do you (Does he/she) find it helpful when speaking? 
$\mathrm{T}-[$ For this item, execution is assessed by observing verbal production during the interview]

8. Gesturing concurrent with verbal activity

Q- Do you (Does he/she) use gestures when you (he/she) speak(s)?/Do you find it helpful to use gestures when you speak (Do you think he/she finds it helpful to use gestures when he/she speaks)?

T- Try to imitate something like that [here clinician suggests imitating an expressive gesture of an idiosyncratic nature complementing a congruent verbal expression]

9. Melodic intonation

Q- Do you (Does he/she) sing or hum sometimes?

T- Try to imitate something like that [here clinician suggests imitating a hummed well-known song]

10. Phonic gesture and emotional content expressions

Q- When you (he/she) are (is) happy, surprised, angry, etc., does this show when you (he/she) speak(s)?

T- Try to imitate something like that. Try to formulate a swearword [here clinician will assess the emotional effect of this last proposal: active involvement, refusal, indifference]

11. Conventional intonation

Q- When you (he/she) are (is) asking a question or giving a command, do you (does he/she) change the tone of your (his/her) voice? Are you aware of it (Do you think he/she is aware of it)?

T- Imagine you have lost the keys of your house. Repeat please after me, "Where are the keys?" [a stressed intonation is suggested by clinician for imitation]. Imagine it is a lovely day [clinician tries to elicit from the aphasic participant an expression such as "What a beautiful day!" or similar]

\section{Paraphrastic abilities and associated phenomena}

12. Definition of terms naming particular objects

Q- If you (he/she) find(s) it difficult to name a particular object, can you (he/she) describe it anyway?

$\mathrm{T}$ - Please, tell me what the following things are: horse, hammer, window.

13. Definition of abstract terms

Q- If you (he/she) find(s) it difficult to name a concept (like for example freedom, shame, etc.) can you (he/she) describe the idea anyway?

$\mathrm{T}$ - Please tell me what the following words mean: anger, love, courage.

14. Circumlocutions

Q- If you (he/she) can't find the correct word for an object, do you (does he/she) talk around it, trying to describe it?

$\mathrm{T}$ - Please tell me what this picture represents [a series of 10 pictures is offered, and only when the individual cannot find the appropriate word the option of circumlocution is positively assessed, as opposed to the option of declaring ignorance or inability]

15. Tip-of-the-tongue phenomenon 
Q- Do you [aphasic individual] sometimes have a word on the tip of your tongue/Do you [conversational partner] feel he/she knows a word, but he/she cannot quite bring it to mind?

$\mathrm{T}$ - Please try to remember this situation or comment on it [gestures exemplifying this situation can be used by clinician)]

16. Paraphasias

Q- When trying to say a word, do you (does he/she) sometimes say another word? Do you (does he/she) make some comments on this circumstance?

$\mathrm{T}$ - Please tell me what this picture represents [a series of 10 pictures is shown, and paraphasias are positively assessed to the extent that the denomination problems elicit some comments. Paraphasia with anosognosia scores 0$]$

\section{Reported speech and associated phenomena}

17. Reported speech

Q- Can you (he/she) relate what somebody said to another person?

$\mathrm{T}$ - Please tell your (wife/ friend ... ) that you have an appointment at the hospital next Tuesday [clinician whispers this message to the participant under examination. Note that no literal repetition is required, but a reported speech formulation such as "clinician tells me that I have an appointment . . ."]

18. Reported speech and phonic gesturing

Q- Do you think you (Does he/she) adopt the voice of another person when reporting something he or she said?

$\mathrm{T}$ - Please try to remember such a situation or comment on it. Try to imitate how a child asks for a toy.

19. Voice imitation

Q- Can you (he/she) imitate the voice of another person? Do you (Does he/she) do it sometimes?

T- Try to imitate the voice of somebody famous (e.g., a famous politician, celebrity, showman) [if the aphasic individual doesn't offer his/her own proposal, a particular case is suggested]

20. Reporting a story

Q- Can you (he/she) relate the story behind a television programme?

$\mathrm{T}$ - Please try to remember now a TV episode you watched recently.

\section{Monitoring abilities and contextualisation cues}

21. Monitoring syllables: Separating syllables in a word

Q- Do you think you (he/she) can separate the syllables in a word? Can you (he/she) pronounce, for example, Ar-Ti-Fi-Cial?

T- How many syllables do these words have? (face, salary, ordinary)

22. Monitoring phrase structure: Sense stress for emphasis

Q- Do you (Does he/she) sometimes split words for emphasis?

T- Try to do that with the following phrases: You are very intelligent! He is magnificent! How terrible!

23. Monitoring syllables with the support of gesturing

Q- Do you (Do you think he/she can) find it helpful to count syllables with your (his/her) fingers?

$\mathrm{T}$ - Try to do that with the following words: intelligent, magnificent, terrible.

24. Ways of saying in context 
Q- Do you (Does he/she) change the way you (he/she) express (-es) yourself (him/herself) according to who you (he/she) are (is) speaking to?

$\mathrm{T}$ - Try to imitate this when speaking to a child.

25. Monochannel communication ability

Q- Do you (Does he/she) normally use a telephone?

$\mathrm{T}$ - Please call my mobile [clinician goes out of the room, a short phone conversation is initiated]

26. Communication ability with absent addressee

Q- Can you (he/she) leave a message on the answering machine?

$\mathrm{T}$ - Try to do that by identifying yourself and suggesting and arrangement for the next week [participant under examination tries to leave a message on an answering machine available for carrying out this item ]

27. Self-correction ability

Q- Do you (Does he/she) sometimes correct your (his/her) own words?

$\mathrm{T}$ - Please try to remember such a situation or comment on it.

28. Hetero-correction ability

Q- Do you (Does he/she) correct another person's expression?

$\mathrm{T}$ - Please try to remember this situation or comment on it.

29. Assessing another's words

Q- Do you (Does he/she) comment on the way another person speaks?

$\mathrm{T}$ - Please try to remember this situation or comment on it.

30. Ability to fill in lexical gaps

Q- Do you (Does he/she) occasionally finish another person's sentences, especially when this person hesitates?

$\mathrm{T}$ - [clinician offers here suspended constructions with lexical gaps, suggesting a filling task for the individual under examination]

\section{Displaced use of language and Theory of Mind (TOM) phenomena}

31. Describing an object or situation not present

Q- Do you think you (he/she) can describe an object or situation not present here, for example your (his/her) house or a place you (he/she) have (has) visited during holidays?

T- Try to do that: to describe, for example, your house.

32. Remembering recent past events

Q- Do you (Does he/she) sometimes speak about things that have happened over the last few days?

$\mathrm{T}$ - Please tell me about something which happened to you last week.

33. Remembering remote past events

Q- Do you (Does he/she) sometimes speak about things that happened a long time ago?

$\mathrm{T}$ - Please tell me something that happened when you were young(er).

34. Anticipating future events

Q- Do you (Does he/she) sometimes talk about plans for tomorrow or the next few days?

T-Please tell me what you think you will be doing tomorrow (at this time, for example).

35. Describing a scene 
Q- Can you (Do you think he/she can) describe a situation and imagine the intentions and/or words of the people involved in it?

$\mathrm{T}$ - Please tell me what this policeman is probably saying to the boys [ $a$ corresponding picture is shown]

36. Ability to contradict and/or to find antonyms

Q- Do you (Does he/she) sometimes say just the opposite of what another person says?

T-Please find the correct match in these cases:

Imagine: I am your uncle. You are my (nephew/niece).

Imagine: I'm selling you my car. You're (buying) my car.

37. Emotion reading

Q- Do you think it is a problem for you (him/her) to perceive whether somebody is sad, angry or happy, etc?

$\mathrm{T}$ - Please identify the emotions shown in the following pictures [clinician shows different pictures demonstrating emotional states]

38. Fictional use of language

Q- Can you (he/she) create a story with imaginary characters?

$\mathrm{T}$ - Please try to remember a well-known tale.

39. Ability to lie

Q- Do you (Does he/she) sometimes tell white lies?

$\mathrm{T}-\mathrm{As}$ a joke, tell me a lie.

40. Expressing sarcasm

Q- Do you (Does he/she) sometimes put on a sarcastic tone of voice? [clinician can offer here an example of an ironic expression]

T- Try to say in a sarcastic tone of voice: "you are really intelligent" "it is really a lovely day". 